\title{
Influence of ammonia on wet-limestone flue gas desulfurization process from coal-based power plant
}

\author{
Tomasz Wypiór ${ }^{1,2}$, and Renata Krzyżyńska ${ }^{1, *}$ \\ ${ }^{1}$ Faculty of Environmental Engineering, Wrocław University of Science and Technology, \\ Wybrzeże Wyspiańskiego 27, 50-370 Wrocław, Poland \\ ${ }^{2}$ RAFAKO S.A., ul. Łąkowa 33, 47-400 Racibórz, Poland
}

\begin{abstract}
The paper presents data concerning the influence of ammonia on wet flue gas desulfurization (WFGD) absorber. Paper presents preliminary results of an industrial scale study on WFGD absorber, that collects flue gases from four boilers with total flue gas flow capacity of the WFGD equal to $1500000 \mathrm{Nm}^{3} / \mathrm{h}$. Each boiler is equipped with selective non-catalytic reduction (SNCR) with urea injection. It was shown, that ammonia present in the flue gas upstream the WFGD increases the $\mathrm{pH}$ of absorption slurry, impacting the desulphurization process. In addition, analysis of particulate matter upstream and downstream the absorber shows an increase of the concentration of ammonium species in the particulate matter about 14 times, as average. Moreover, a non-optimized denitrification process can cause a high $\mathrm{NH}_{4}{ }^{+}$concentration in the absorption slurry (up to $768 \mathrm{mg} / \mathrm{L}$ ) and raw wastewater (up to $891 \mathrm{mg} / \mathrm{L}$ ).
\end{abstract}

\section{Introduction}

Forced oxidation wet-limestone scrubbers are the majority of flue gas desulfurization units installed in coal-based power plants. The removal of nitrogen oxides is carried out in either selective catalytic reduction (SCR) modules or employing selective non-catalytic reduction (SNCR) method. Both are based on nitrogen oxides (NOx) reduction to molecular nitrogen with the use of ammonia gas, which is commonly obtained from thermal decomposition of ammonia water or urea. Both SNCR and SCR technologies are interrelated with a stream of unreacted ammonia, referred as the ammonia slip. Substantial increase of ammonia slip can occur due to poor SNCR design and optimization, as well as deterioration of SCR catalysts. The ammonia is present in the flue gas in gaseous form or the form of particulate matter composed of ammonium salts $[1,2]$.

In wet-limestone scrubbers, the majority of ammonia slip is absorbed in the limestonegypsum slurry and is present as ammonium $\left(\mathrm{NH}_{4}^{+}\right)$ions. In theory, presence of ammonium ions has a positive effect on the desulfurization process due to the increased efficiency of $\mathrm{SO}_{2}$ removal. However, information is scarce with regard to the effect on $\mathrm{pH}$ value of the

\footnotetext{
*Corresponding author: renata.krzyzynska@pwr.edu.pl
} 
slurry - a critical parameter in the control of limestone dosing, dissolution and gypsum formation.

\subsection{Source of ammonia in flue gas}

The principle of operation of denitrification systems is based on reactions of nitrogen oxides with gaseous ammonia - equations (1-3) or urea - equations (4-5) with water and nitrogen as reaction products $[3,4]$ :

$$
\begin{gathered}
4 \mathrm{NO}+4 \mathrm{NH}_{3}+\mathrm{O}_{2} \leftrightarrow 4 \mathrm{~N}_{2}+6 \mathrm{H}_{2} \mathrm{O} \\
\mathrm{NO}+\mathrm{NO}_{2}+2 \mathrm{NH}_{3} \leftrightarrow 2 \mathrm{~N}_{2}+3 \mathrm{H}_{2} \mathrm{O} \\
2 \mathrm{NO}_{2}+4 \mathrm{NH}_{3}+\mathrm{O}_{2} \leftrightarrow 3 \mathrm{~N}_{2}+6 \mathrm{H}_{2} \mathrm{O} \\
4 \mathrm{NO}+2\left(\mathrm{NH}_{2}\right)_{2} \mathrm{CO}+2 \mathrm{H}_{2} \mathrm{O} \leftrightarrow 4 \mathrm{~N}_{2}+6 \mathrm{H}_{2} \mathrm{O}+2 \mathrm{CO}_{2} \\
6 \mathrm{NO}_{2}+4\left(\mathrm{NH}_{2}\right)_{2} \mathrm{CO}+4 \mathrm{H}_{2} \mathrm{O} \leftrightarrow 7 \mathrm{~N}_{2}+12 \mathrm{H}_{2} \mathrm{O}+4 \mathrm{CO}_{2}
\end{gathered}
$$

In SCR, the reducing agent is injected into the flue gas upstream the catalyst. The typical industrial vanadium-titanium catalyst operates at a temperature window of $300-450^{\circ} \mathrm{C}$, near the molar ratio of 1:1 with regard to equations (1) and (4) [3]. To achieve good NOx removal efficiency, proper mixing of $\mathrm{NH}_{3}$ with flue gas is essential. Ammonia is diluted with air before the injection and is introduced to the flue gas stream by a system of nozzles. To obtain greater homogeneity of the flue gas/ammonia mixture, a static mixer can be placed between the injection point and SCR catalyst. At greater $\mathrm{NH}_{3}$ to $\mathrm{NOx}$ ratios, better NOx removal efficiency can be reached, but the amount of unreacted ammonia can increase considerably [4].

In comparison to SCR, SNCR is based on direct reagent injection to the boiler combustion chamber, and the reduction of NOx is strongly temperature dependent - with temperature window between 800 and $1100^{\circ} \mathrm{C}[4,5]$. Above this range, ammonia is oxidized, and nitrogen oxides are formed - equation (6). Below this range, the reaction rate is inhibited and unreacted ammonia is present in the flue gas stream [4].

$$
4 \mathrm{NH}_{3}+5 \mathrm{O}_{2} \leftrightarrow 4 \mathrm{NO}+6 \mathrm{H}_{2} \mathrm{O}
$$

The temperature of flue gas fluctuates with boiler load changes, making it difficult to maintain injection in reaction temperature zone. To ensure reagent injection in the temperature window, several levels of injection are typically installed. Proper mixing of flue gas with the reagent is vital to achieve high abatement rate and low $\mathrm{NH}_{3}$ slip. However, a homogeneous distribution is difficult due to hot gas viscosity, an issue, which has often causes high ammonia slip in plants that use the ammonia water as a reducing agent. Difference between ammonia and urea is shown on Fig. 1.

Urea solution droplets that are introduced to the combustion chamber do not react immediately. Water evaporates first, leaving a droplet of solid urea that decomposes into $\mathrm{NH}_{2}$-species radicals. The region, in which the decomposition and a deNO $\mathrm{x}_{\mathrm{x}}$ reaction occur can be determined in advance by urea solution droplet size and the resulting penetration depth. The usage of urea in the SNCR process ensures a higher penetration depth at lower energy consumption in comparison with ammonia water. Compared to urea, ammonia evaporates immediately from the solution after being introduced to the combustion chamber. Mixing can be improved by nozzle design and more substantial mass flow of 
dilution water. In addition to mixing, reagent droplet size is a relevant parameter. Drops that are too small evaporate rapidly and react per equation (6), reducing overall efficiency. On the other hand, large drops cause the ammonia to react at temperatures below the optimum window, resulting in increased $\mathrm{NH}_{3}$ slip [4-6].
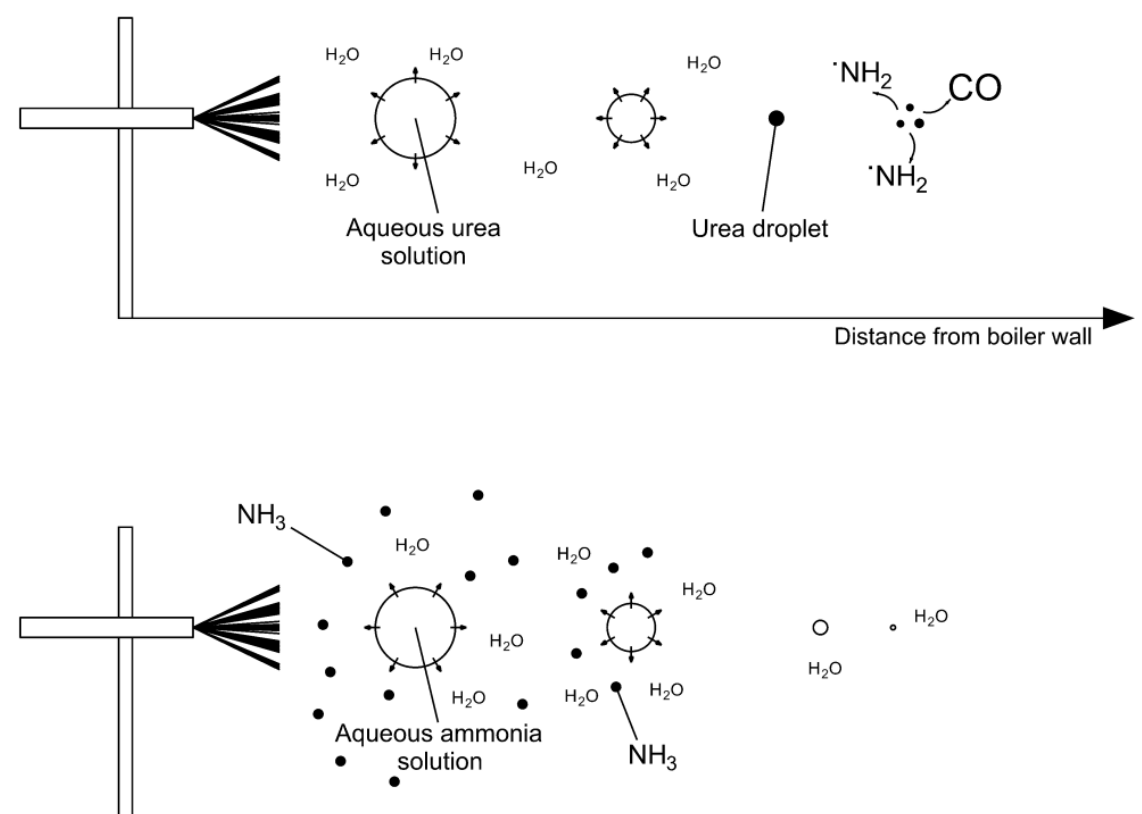

Distance from boiler wall

Fig. 1. Comparison between urea and ammonia water injection into the combustion chamber.

\subsection{Ammonia and particulates}

Ammonia is readily adsorbed on the fly ash present in the flue gas stream. Zhao Y. et al. [7] reports that $80 \%$ of the ammonia present in the flue gas is adsorbed onto the ash. The adsorption efficiency is strongly dependent on ash composition and ash formation conditions. Ammonia reacts directly sulphur trioxide $\left(\mathrm{SO}_{3}\right)$ and water present in the flue gas to produce particulates of ammonium sulphate $\left(\left(\mathrm{NH}_{4}\right)_{2} \mathrm{SO}_{4}\right)$ and ammonium bisulphate $\left(\mathrm{NH}_{4} \mathrm{HSO}_{4}\right)$ as shown in equations (7), (8) and (9) [8]:

$$
\begin{gathered}
\mathrm{SO}_{2}+1 / 2 \mathrm{O}_{2} \rightarrow \mathrm{SO}_{3} \\
2 \mathrm{NH}_{3}+\mathrm{SO}_{3}+\mathrm{H}_{2} \mathrm{O} \leftrightarrow\left(\mathrm{NH}_{4}\right)_{2} \mathrm{SO}_{4} \\
\mathrm{NH}_{3}+\mathrm{SO}_{3}+\mathrm{H}_{2} \mathrm{O} \leftrightarrow \mathrm{NH}_{4} \mathrm{HSO}_{4}
\end{gathered}
$$

Flue gas containing acidic pollutants and ammonia (gaseous, or in the form of salts and adsorbed on the fly ash) is then contacted with the absorption slurry in the WFGD. 


\section{Effect of ammonia on WFGD}

\subsection{Effect on plant operation}

Ammonia is an alkaline compound and theoretically should have a positive impact on the desulfurization efficiency. However, most of the WFGD systems are controlled by automatic regulation system. In such systems, limestone dosing is dependent on the $\mathrm{pH}$ measurement of the slurry. WFGD typically operate between $\mathrm{pH}$ of 5-6 [9], with the value pre-set in the master control system. Slurry $\mathrm{pH}$ is lowered by the absorption of gaseous acidic components and is adjusted by the addition of alkaline limestone $\left(\mathrm{CaCO}_{3}\right)$ suspension. A substantial ammonia slip can raise the $\mathrm{pH}$ value of the slurry. It has an adverse effect on the control system, causing it to decrease the dosage of fresh $\mathrm{CaCO}_{3}$. This can result in a drop in desulfurization efficiency. This presents an issue when the power plant is equipped with SNCR, and most of the ammonia slip is in the form of gaseous $\mathrm{NH}_{3}$.

\subsection{Effect on desulfurization}

Takashina et al. [10] studied the effect of ammonium concentration on $\mathrm{SO}_{2}$ absorption rate in a model WFGD. In the study, flue gas was prepared by mixing $\mathrm{N}_{2}, \mathrm{O}_{2}, \mathrm{CO}_{2}$, and $\mathrm{SO}_{2}$ and introduced to a stirred reactor with limestone suspension. By varying the molar concentration of ammonium sulphate in a $1 \mathrm{wt} . \%$ limestone suspension, the $\mathrm{SO}_{2}$ absorption rate was measured and was reported to increase with the rise of ammonium concentration, as shown in Table 1.

Table 1. Effect of ammonium concentration on the $\mathrm{SO}_{2}$ absorption rate. $\mathrm{SO}_{2}$ concentration 3000 [ppm], temp.: $50\left[{ }^{\circ} \mathrm{C}\right], \mathrm{CaCO}_{3}$ concentration: 1 [wt.\%] [10].

\begin{tabular}{|c|c|}
\hline $\mathbf{N H}_{4}{ }^{+}[\mathbf{m o l} / \mathbf{L}]$ & $\mathbf{S O}_{2}$ absorption rate $\left[\mathbf{k m o l} / \mathbf{m}^{\mathbf{2}} \mathbf{h}\right] \cdot \mathbf{1 0}^{-3}$ \\
\hline 0.020 & 2.48 \\
\hline 0.100 & 2.64 \\
\hline 0.200 & 2.86 \\
\hline 0.400 & 2.97 \\
\hline
\end{tabular}

It is worth noting, that ammonium molar concentrations assumed for the test considerably exceed the concentration of $567.9 \mathrm{mg} / \mathrm{L}$ measured in an industrial WFGD reported by $\mathrm{T}$. Cheng [3].

\subsection{Effect on PM2.5 emission}

T. Cheng mapped the migration of ammonia and ammonia species through WFGD. Reported ammonium removal efficiency in WFGD was measured as $62.8 \%$. $\mathrm{NH}_{3}$, due to its water solubility, was reported to be absorbed by the slurry at efficiency of $89.1 \%$.

The evaporation from the slurry surface and the entrainment of liquid from the slurry droplets releases ammonia in the form of $\mathrm{NH}_{4}{ }^{+}$and $\mathrm{NH}_{3}$. The elevated temperature of the flue gas causes ammonia to evaporate from the slurry. In the moist and cool upper section of the scrubber, ammonia dissolves in condensed water and deposits on the surfaces of other particles, or undergoes homogeneous nucleation which generates new submicron particles (Fig. 2). Z. Li et al. [1] reported an increase of the conversion of ammonia slip to $\mathrm{NH}_{4}{ }^{+}$found in the PM2.5 at the WFGD outlet. The increase of primary $\mathrm{NH}_{4}^{+}$and $\mathrm{SO}_{4}{ }^{2-}$ aerosol emissions were 18.9 and 4.2 times with respect to the inlet. 


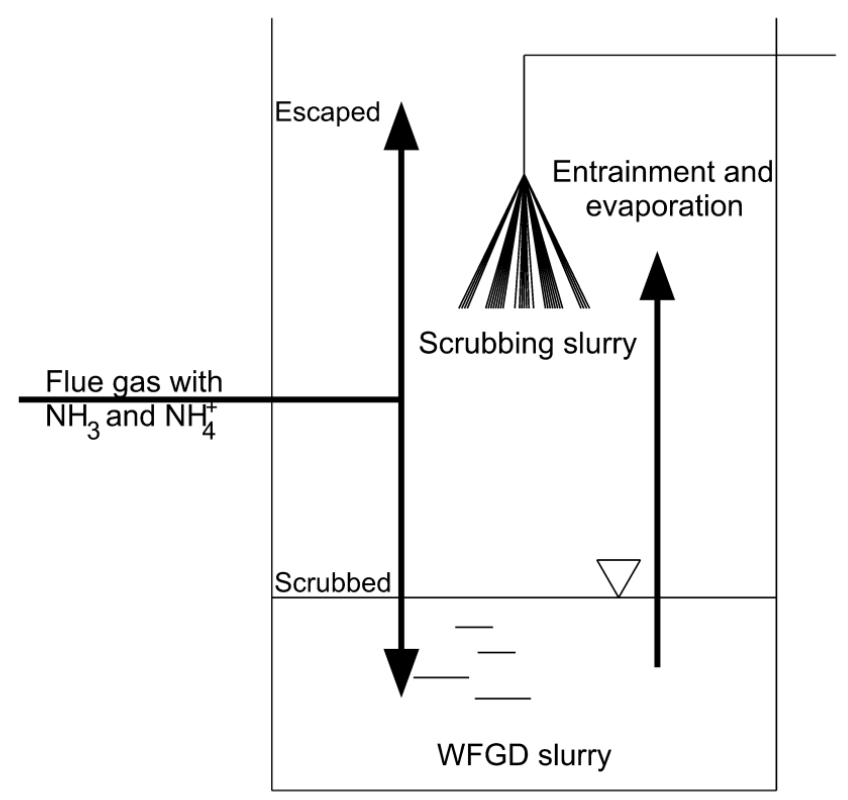

Fig. 2. Transfer of $\mathrm{NH}_{3}$ and $\mathrm{NH}_{4}{ }^{+}$in the WFGD.

\section{Experimental}

An industrial scale study was performed on a single Polish WFGD operating on flue gases from four boilers fired with hard coal and equipped with SNCR. Design capacity of the WFGD is equal to $1500000 \mathrm{Nm}^{3} / \mathrm{h}$. During the test, boilers were operating on their maximum capacity and $\mathrm{DeNO}_{\mathrm{x}}$ systems were set to reach the guaranteed $\mathrm{NO}_{\mathrm{x}}$ value below $200 \mathrm{mg} / \mathrm{Nm}^{3}$ ref. (normal conditions at 6\% reference oxygen level). Average urea consumption during the measurement period was $256.94 \mathrm{~kg} / \mathrm{h}$ for a single boiler (Fig. 3).

SNCR was coupled with acoustic gas temperature measurement system in order to inject urea solution in the temperature window. The subject was the measurement of ammonia content in flue gas in selected measurement cross-sections and selected process media. Measurements were performed by an external certified laboratory with accreditation certificate of testing No. AB550.

Measurements in the flue gas stream $(\mathrm{G} 1, \mathrm{G} 2)$ were performed to analyse the WFGD inlet ammonia concentration, as well as ammonium concentration in the fly ash. Schematic of measurement points was shown on Fig. 4. Gaseous ammonia was measured continuously by Gasmet DX 4000 FT-IR spectrometer. Ammonium compounds in fly ash were measured by sampling and determined as ammonia in the aqueous extract in accordance with PN-ISO 7150-2:2002. Samples of absorption slurry (L1) an draw wastewater (L2) were extracted manually by sampling and were transferred to the external laboratory. Continuous slurry $\mathrm{pH}$ measurement was performed by using a Liquiline M CM42 transmitter with Pfaudler $\mathrm{pH}$ probe type 03/04. 


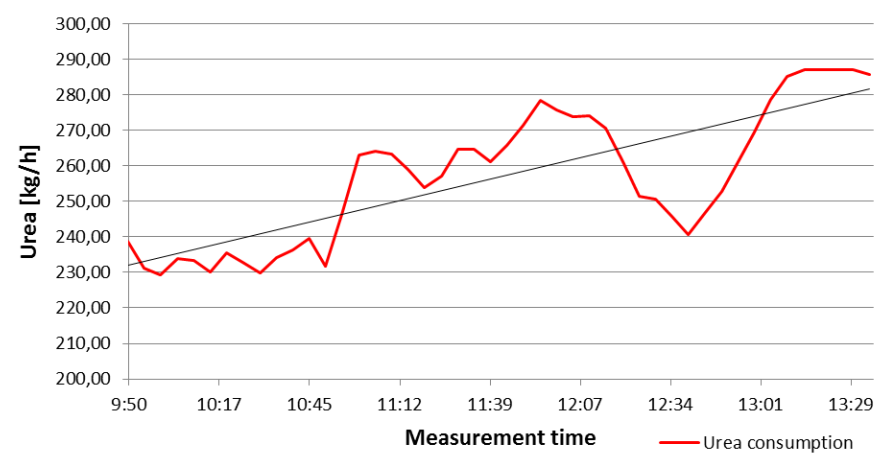

Fig. 3. Urea consumption.

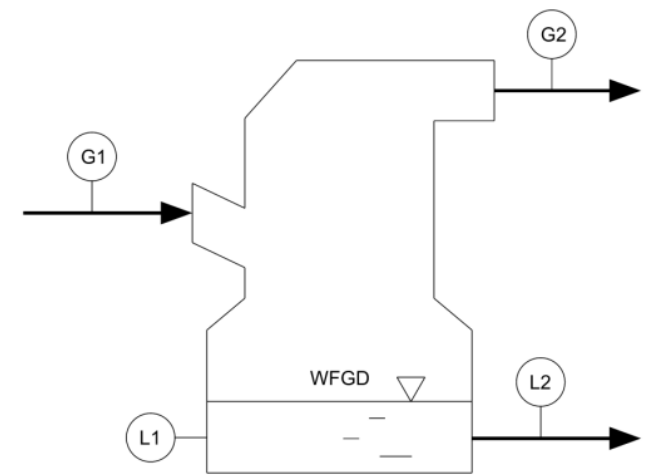

Fig. 4. Location of measurement points.

\section{Results and discussion}

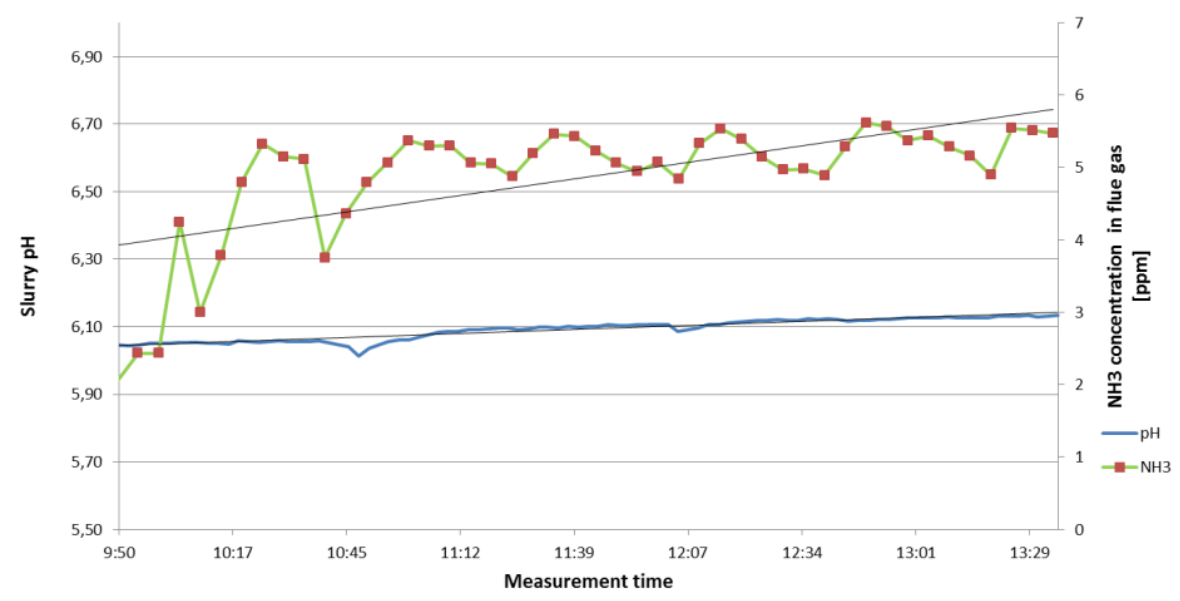

Fig. 5. Comparison between $\mathrm{pH}$ value and concentration of $\mathrm{NH}_{3}$ at WFGD inlet. 
As shown on Fig. 5, ammonia slip from has a slight but persistent effect on the absorption slurry $\mathrm{pH}$ value. An increase in $\mathrm{pH}$ disturbs the fresh $\mathrm{CaCO}_{3}$ dosing regulation system. In power plants that have a poorly optimized SNCR or deteriorated SCR system, such disturbances might be substantial and regulation system might require a correction factor.

Table 2. Influence of WFGD operation on ammonia content in ash.

\begin{tabular}{|c|c|c|c|c|c|c|}
\hline & \multicolumn{3}{|c|}{ WFGD inlet } & \multicolumn{3}{c|}{ WFGD outlet } \\
\hline Sample & 1 & 2 & 3 & 4 & 5 & 6 \\
\hline $\mathrm{NH}_{3}[\mathrm{mg}]$ & 0.15 & 0.12 & 0.12 & 3.23 & 0.83 & 1.31 \\
\hline
\end{tabular}

It was tested, that the operation of WFGD significantly increases $\mathrm{NH}_{4}{ }^{+}$emission in the form of particulate matter - Table 2. The increase of ammonium species in the particulate matter at scrubber outlet is 13.8 times as average. Results are in agreement with those presented by $\mathrm{Z}$. Li et al.

Table 3. Absorption slurry measurement results $-\mathrm{L} 1$.

\begin{tabular}{|c|c|c|c|}
\hline Parameter & Unit & \multicolumn{2}{|c|}{ Value } \\
\hline Time & hh:mm & $09: 00$ & $13: 00$ \\
\hline Ammonium nitrogen as $\mathrm{NNH}_{4}$ & $\mathrm{mg} / \mathrm{L}$ & 559 & 596 \\
\hline Ammonia as $\mathrm{NH}_{4}{ }^{+}$ & $\mathrm{mg} / \mathrm{L}$ & 720 & 768 \\
\hline${\text { Nitrate nitrogen as } \mathrm{N}_{\mathrm{NO} 3}}^{-} \mathrm{mg} / \mathrm{L}$ & 198 & 216 \\
\hline Nitrates as $\mathrm{NO}_{3}{ }^{-}$ & $\mathrm{mg} / \mathrm{L}$ & 877 & 956 \\
\hline${\text { Nitrite nitrogen } \mathrm{N}_{\mathrm{NO} 2}}^{-} \mathrm{mg} / \mathrm{L}$ & 0.224 & 0.278 \\
\hline Nitrites as $\mathrm{NO}_{2}{ }^{-}$ & $\mathrm{mg} / \mathrm{L}$ & 0.736 & 0.913 \\
\hline
\end{tabular}

Table 4. Raw wastewater measurement results $-\mathrm{L} 2$.

\begin{tabular}{|c|c|c|c|}
\hline Parameter & Unit & \multicolumn{2}{|c|}{ Value } \\
\hline Time & $\mathrm{hh}: \mathrm{mm}$ & $9: 00$ & $13: 00$ \\
\hline Ammonium nitrogen as $\mathrm{N}_{\mathrm{NH} 4}$ & $\mathrm{mg} / \mathrm{L}$ & 670 & 590 \\
\hline Ammonia as $\mathrm{NH}_{4}{ }^{-}$ & $\mathrm{mg} / \mathrm{L}$ & 891 & 760 \\
\hline Nitrate nitrogen as $\mathrm{N}_{\mathrm{NO}}$ & $\mathrm{mg} / \mathrm{L}$ & 241 & 214 \\
\hline Nitrates as $\mathrm{NO}_{3}{ }^{-}$ & $\mathrm{mg} / \mathrm{L}$ & 1067 & 947 \\
\hline Nitrite nitrogen as $\mathrm{N}_{\mathrm{NO} 2}$ & $\mathrm{mg} / \mathrm{L}$ & 0.223 & 0.271 \\
\hline Nitrites as $\mathrm{NO}_{2}{ }^{-}$ & $\mathrm{mg} / \mathrm{L}$ & 0.732 & 0.890 \\
\hline
\end{tabular}

Denitrification systems are responsible for the large concentration of nitrogen species in wastewater - Table 3, 4. Such wastewater must be treated to remove the nitrogen prior to discharge to the environment, as it is a considerable danger - especially to aquatic life.

\section{Conclusions}

Large scale limestone WFGD's tests showed that ammonium compounds have negative effect on desulfurization process, in the contrary to some laboratory tests. A substantial ammonia slip can raise the $\mathrm{pH}$ value of the slurry. It has an adverse effect on the control system, causing decreasing the dosage of fresh $\mathrm{CaCO}_{3}$. This can result in a drop in desulfurization efficiency. This presents an issue when the power plant is equipped with $\mathrm{SNCR}$, and most of the ammonia slip is in the form of gaseous $\mathrm{NH}_{3}$. Moreover, the operation of WFGD significantly increases $\mathrm{NH}_{4}{ }^{+}$emission in the form of particulate matter 
This work was financed by the Polish Ministry of Sciences and Higher Education and partially by Wroclaw University of Science and Technology, Faculty of Environmental Engineering and RAFAKO S.A. Funds were allocated from "Implementation Doctorate" programme.

\section{References}

1. Z. Li, J. Jiang, Z. Ma, O. A. Fajardo, J. Deng, L. Duan, Environ. Pollut. 230, 10, 655662 (2017)

2. T. Cheng, C. Zheng, L. J. Yang, H. Wu, H. Fan, Fuel 238, 18-25 (2019)

3. J. J. Schreifels, S. Wang, J. Hao, Front. Energy 6, 1, 98-105 (2012)

4. T. Lecomte, Best Available Techniques (BAT) Reference Document for Large Combustion Plants (2017)

5. B. von der Heide, SNCR Process - Best Available Technology for NOx Reduction in Waste To Energy Plants (POWER-GEN Eur., 3-5, 2008)

6. J. L. Sorrels, EPA Air Pollution Control Cost Manual ( $6^{\text {th }}$ ed., Section 4.2, Chapter 1, 2016)

7. Y. Zhao, W. Yang, J. Zhou, Z. Wang, J. Liu, K. Cen, J. Fuel. Chem. Technol. 43, 3, 266-272 (2015)

8. B. G. Miller, Clean Coal Engineering Technology (2011)

9. M. Głomba, J. Air Waste Manag. Assoc. 60, 8, 1009-1016 (2010)

10. T. Takashina, S. Honjo, N. Ukawa, K. Iwashita, J. Chem. Eng. Japan 35, 2, 197-204 (2002) 